\title{
Discovery of novel small molecule modulators of Clavibacter michiganensis subsp. michiganensis
}

\author{
Xiulan Xu'ti, Anand Kumar ${ }^{2}$, Loïc Deblais², Ruby Pina-Mimbela ${ }^{2}$, Corey Nislow ${ }^{3}$, \\ James R. Fuchs ${ }^{4}$, Sally A. Miller ${ }^{1}$ and Gireesh Rajashekara ${ }^{2 *}$
}

${ }^{1}$ Department of Plant Pathology, Ohio Agricultural Research and Development Center, The Ohio State University, Wooster, $\mathrm{OH}$, USA, ${ }^{2}$ Food Animal Health Research Program, Department of Veterinary Preventive Medicine, The Ohio State University, Wooster, OH, USA, ${ }^{3}$ Pharmaceutical Sciences, University of British Columbia, Vancouver, BC, Canada, ${ }^{4}$ College of Pharmacy, The Ohio State University, Columbus, OH, USA

OPEN ACCESS

Edited by:

Tzi Bun Ng,

The Chinese University of Hong Kong,

China

Reviewed by:

Dmitri Debabov,

NovaBay Pharmaceuticals, USA

Ximin Zeng,

University of Tennessee, Knoxville,

USA

*Correspondence:

Gireesh Rajashekara

rajashekara.2@osu.edu

${ }^{\dagger}$ Present address: Xiulan Xu,

Beijing Vegetable Research Center Beijing Academy of Agriculture and

Forestry Sciences, Beijing, China

Specialty section:

This article was submitted to Antimicrobials, Resistance and Chemotherapy,

a section of the journa

Frontiers in Microbiology

Received: 12 August 2015 Accepted: 28 September 2015

Published: 19 October 2015

Citation

Xu X, Kumar A, Deblais L, Pina-Mimbela R, Nislow C, Fuchs JR, Miller SA and Rajashekara G (2015)

Discovery of novel small molecule modulators of Clavibacter michiganensis subsp. michiganensis.

Front. Microbiol. 6:1127. doi: 10.3389/fmicb.2015.01127
Clavibacter michiganensis subsp. michiganensis (Cmm) is a Gram-positive seedtransmitted bacterial phytopathogen responsible for substantial economic losses by adversely affecting tomato production worldwide. A high-throughput, cell-based screen was adapted to identify novel small molecule growth inhibitors to serve as leads for future bactericide development. A library of 4,182 compounds known to be bioactive against Saccharomyces cerevisiae was selected for primary screening against Cmm wild-type strain C290 for whole-cell growth inhibition. Four hundred sixty-eight molecules (11.2\% hit rate) were identified as bacteriocidal or bacteriostatic against $\mathrm{Cmm}$ at $200 \mu$ M. Seventy-seven candidates were selected based on Golden Triangle analyses for secondary screening. Secondary screens showed that several of these candidates were strain-selective. Several compounds were inhibitory to multiple Cmm strains as well as Bacillus subtilis, but not to Pseudomonas fluorescens, Mitsuaria sp., Lysobacter enzymogenes, Lactobacillus rhamnosus, Bifidobacterium animalis, or Escherichia coli. Most of the compounds were not phytotoxic and did not show overt host toxicity. Using a novel 96-well bioluminescent $\mathrm{Cmm}$ seedling infection assay, we assessed effects of selected compounds on pathogen infection. The 12 most potent novel molecules were identified by compiling the scores from all secondary screens combined with the reduction of pathogen infection in planta. When tested for ability to develop resistance to the top-12 compounds, no resistant $\mathrm{Cmm}$ were recovered, suggesting that the discovered compounds are unlikely to induce resistance. In conclusion, here we report top-12 compounds that provide chemical scaffolds for future $\mathrm{Cmm}$-specific bactericide development.

Keywords: $\mathrm{Cmm}$, tomato canker, bioluminescent imaging, small molecule inhibitors, high throughput screening

\section{INTRODUCTION}

Tomato bacterial canker, caused by Clavibacter michiganensis subsp. michiganensis (Cmm), is one of the most important diseases of tomato in temperate zones and greenhouses worldwide (Gleason et al., 1993). Cmm is a Gram-positive bacterium that infects the plant through wounds, and natural openings such as stomata and hydathodes, after which it moves into the xylem 
(Carlton et al., 1998; Gartemann et al., 2003; Sharabani et al., 2013). Severe yield loss can result from stunting and wilting of the plant, and "bird's eye" lesions on the fruit. It is known that $\mathrm{Cmm}$ is a strong endophyte and is easily disseminated directly into vascular tissue during transplanting, pruning, and harvesting under current tomato production systems (Chang et al., 1991; Kawaguchi et al., 2010). At present, control and management of tomato bacterial canker relies primarily on the use of clean seed, healthy transplant practices, and crop rotation. However, once disease is established in a field or greenhouse, chemical treatment such as copper-based bactericides or antibiotics have a limited impact on reducing the disease burden (Hausbeck et al., 2000; Miller and Ivey, 2005). Cmm control is further complicated by the development of bactericide resistance (Cooskey, 1990). Therefore, novel compounds with new targets are urgently needed for future management of tomato bacterial canker.

High throughput (HTP) screening has proven to be useful in identifying small molecule anti-infectives targeting a specific protein or by inhibiting pathogen (Hong-Geller and Micheva-Viteva, 2013). Small, drug-like molecules (e.g., less than $500 \mathrm{Da}$ with a cLogP less than 5) are particularly attractive because they can often pass through cell membranes. Successful examples include inhibitors to Type III secretion and biofilm formation by Pseudomonas (Junker and Clardy, 2007; Arnoldo et al., 2008; Aiello et al., 2010), and novel kinase inhibitors to Toxoplasma gondii and acetyl transferase inhibitors in Escherichia coli (Pereira et al., 2009; Kamau et al., 2012). Identification of "hits" from such HTP screens can provide the starting point for chemical tools to probe mechanisms of action and for drug development for infectious diseases.

A limited number of studies have used HTP screening in plant-pathogen models. Schreiber et al. (2008) developed a 96-well plate liquid assay to screen small molecules that prevent symptoms caused by Pseudomonas syringae on Arabidopsis thaliana and uncovered a family of sulfanilamide compounds that reduce bacterial virulence in planta (Schreiber et al., 2008). Using a similar approach, further investigation of small molecules targeting the fungal phytopathogen Fusarium graminearum identified two compounds, sulfamethoxazole and indole alkaloid gramine, that reduced pathogen infection in wheat (Schreiber et al., 2011). Nonetheless, no studies have been reported that identify small molecules that interact with plant pathogenic Gram-positive bacteria.

In this study we screened a validated library of 4,182 yeast-active molecules or, "yactives" against $\mathrm{Cmm}$ by using a whole-cell based HTP screening approach and 77 of the 468 hits were further evaluated for their sensitivity, specificity, and phytotoxicity (Wallace et al., 2011). Candidates were further tested for mammalian cytotoxicity and for $\mathrm{Cmm}$ inhibition in tomato seedlings using a bioluminescent Cmm strain (Xu et al., 2010). A structural analysis of the 12 most promising small molecules identified chemical scaffolds for potential bactericide development for future applications.

\section{MATERIALS AND METHODS}

\section{Chemical Library and Bacterial Strains}

A small molecule library containing 4,182 compounds 'yactives' was designed in collaboration with ChemBridge (San Diego, CA, USA) and was supplied in a 96-well format in $10 \mathrm{mM}$ dimethyl sulfoxide (DMSO). We used the 'yactive' library because in our previous study it increased hit rate by several folds when screened for model bacteria such as Gram negative E. coli $(\sim 12$-fold) and Gram positive Bacillus subtilis (sixfold) compared to screening random selected compounds library (Wallace et al., 2011). Bacterial strains used in this study are listed in Table 1. Bacterial strains were streaked out from $-80^{\circ} \mathrm{C}$ freezer stock onto nutrient broth-yeast agar (NBY) and LB.

\section{Primary Screen}

Primary screening was conducted with $\mathrm{Cmm}$ wild-type strain C290, which was originally isolated from tomato in Ohio and characterized as type C by REP-PCR (Louws et al., 1998). Briefly, a fresh bacterial culture was inoculated into $5 \mathrm{ml}$ NBY broth and grown at $28^{\circ} \mathrm{C}$ with shaking at $200 \mathrm{rpm}$. After $24 \mathrm{~h}$ of incubation, the culture was diluted in NBY broth to an $\mathrm{OD}_{600}$ of $0.05\left(5 \times 10^{7} \mathrm{CFU} / \mathrm{ml}\right)$ using a Genosys 20 spectrophotometer (Thermo Scientific, Rockford, IL, USA). To an aliquot of $100 \mu \mathrm{l}$ diluted culture in each well in a 96-well plate, $1 \mu$ l of compound was added using a slotted pin tool (V and P Scientific, San Diego, CA, USA) for a final concentration of $200 \mu \mathrm{M}$. Controls (four replicates/plate) containing $1 \mu \mathrm{l}$ DMSO, $1 \mu \mathrm{l}$ chloramphenicol $(20 \mu \mathrm{g} / \mu \mathrm{l})$, no compound and $100 \mu \mathrm{l}$ of cell-free media were included in each test plate. Plates were incubated at $28^{\circ} \mathrm{C}$ with

TABLE 1 | List of bacterial strains tested in the primary and secondary screens.

\begin{tabular}{|c|c|c|}
\hline Bacteria & Strain & Reference \\
\hline $\begin{array}{l}\text { Clavibacter subsp. } \\
\text { michiganensis }\end{array}$ & $\begin{array}{l}\text { C290 } \\
\text { BL-Cmm17 } \\
\text { A226, A300CMM12B } \\
\text { 08-687, 09-158, 09-159, } \\
\text { VF3-1-08, VF6-7-08, } \\
\text { 09-176, SM101-09, } \\
\text { 09-157, SM287-11, } \\
\text { SM288-11, SM610-11, } \\
\text { SM611-11, SM614-11, } \\
\text { SM615-11 }\end{array}$ & $\begin{array}{l}\text { Louws et al., } 1998 \\
\text { Xu et al., } 2010 \\
\text { Louws et al., } 1998 \\
\text { Different clonal groups of } \\
\text { Cmm strains isolated from } \\
\text { greenhouse tomatoes in } \\
\text { USA, Canada, and } \\
\text { Guatemala }\end{array}$ \\
\hline $\begin{array}{l}\text { Pseudomonas } \\
\text { fluorescens } \\
\text { Bacillus subtilis }\end{array}$ & $\begin{array}{l}\text { Wood1 } \\
\text { GB03 }\end{array}$ & $\begin{array}{l}\text { Plant beneficial bacteria, } \\
\text { provided by Dr. Brian } \\
\text { McSpadden Gardener }\end{array}$ \\
\hline $\begin{array}{l}\text { Mitsuaria sp. } \\
\text { Lysobacter } \\
\text { enzymogenes }\end{array}$ & $\begin{array}{l}\text { H24L5A } \\
\text { C3 }\end{array}$ & \\
\hline $\begin{array}{l}\text { Lactobacillus } \\
\text { rhamnosus }\end{array}$ & LGG & $\begin{array}{l}\text { Human gut bacteria, lab } \\
\text { collection }\end{array}$ \\
\hline $\begin{array}{l}\text { Bifidobacterium } \\
\text { animalis }\end{array}$ & $\mathrm{Bb} 12$ & \\
\hline Escherichia coli & Nissle & \\
\hline
\end{tabular}


shaking at $200 \mathrm{rpm}$ for $24 \mathrm{~h}$. The end-point $\mathrm{OD}_{595}$ was measured using a Sunrise ${ }^{\mathrm{TM}}$ Tecan kinetic microplate reader (Tecan US, Inc., San Jose, CA, USA). A parameter Z' to evaluate the quality of the HTP screen was calculated using formula 1 (Zhang et al., 1999). The growth inhibition rate was calculated as described by formula 2 . The culture in wells with $\geq 99 \%$ growth inhibition was streaked onto fresh NBY agar, as were the sterility, antibiotic and no compound control wells. Bacterial growth was measured on the plate after $48 \mathrm{~h}$ at $28^{\circ} \mathrm{C}$. Based on the recovery of $\mathrm{Cmm}$ on NBY, the compound was scored as either "static" or "cidal."

Formula (1): $Z^{\prime}=1-\left(3 \sigma_{c^{+}}+3 \sigma_{c^{-}}\right) /\left|\mu_{c^{+}}-\mu_{c^{-}}\right|$, where $\sigma_{\mathrm{c}^{+}}, \sigma_{\mathrm{c}^{-}}, \mu_{\mathrm{c}^{+}}$, and $\mu_{\mathrm{c}^{-}}$are the standard deviation and average of positive (DMSO amended) and negative controls (chloramphenicol amended).

Formula (2): Inhibition rate $=\left(\mu_{\mathrm{c}^{+}}-\mathrm{X}\right) /\left(\mu_{\mathrm{c}^{+}}-\mu_{\mathrm{c}^{-}}\right)^{*} 100 \%$, where $\mu_{c^{+}}$, and $\mu_{c^{-}}$are the average OD of positive and negative controls, $\mathrm{X}$ is the $\mathrm{OD}$ in well with the small molecule compound.

\section{Secondary Screen with Selected Compounds}

A structural analysis of the primary screen data for 468 hit compounds was conducted. The structural descriptor strings (SMILES) were subsequently converted into ChemDraw structures using ChemDraw for Excel. The compounds were exported to ChemDraw as a SD file using ChemFinder. ChemFinder resulted in the rapid identification of compounds containing the same structural motifs. The ChemDraw files of the hits were manually sorted into structural groups to establish preliminary structure-activity relationships (SARs). Finally, hits were prioritized for secondary screens based on their adherence to Lipinski’s rule of 5 (Lipinski et al., 1997).

Seventy-seven selected compounds were re-ordered from ChemBridge in a 96-well format as a powder. The compounds were dissolved in $100 \mu \mathrm{l} \mathrm{DMSO}$ and stored at $-80^{\circ} \mathrm{C}$ until used. Five tests were carried out to evaluate the sensitivity and specificity of selected compounds, including testing: (1) multiple Cmm strains from different clonal groups as listed in Table 1; (2) the minimum inhibitory concentration (MIC) for $\mathrm{Cmm}$ growth; (3) the minimum bacteriocidal concentration (MBC) for $\mathrm{Cmm}$ (Ling et al., 2015); (4) effects on growth of plant beneficial bacteria and human gut bacteria listed in Table 1; and (5) cytotoxicity of the most potent compounds to Caco- 2 cells. In addition, ability of $\mathrm{Cmm}$ to develop resistance to selected compounds was tested.

Screening for growth inhibition of $\mathrm{Cmm}$ strains, plant beneficial bacteria and human gut bacteria was set up similarly to the initial screen using $1 \mu \mathrm{l}$ of $2 \mu \mathrm{mol}$ suspensions of each compound. Plates were incubated in a Sunrise ${ }^{\mathrm{TM}}$ Tecan microplate reader for kinetic measurement of growth every $15 \mathrm{~min}$ for $24 \mathrm{~h}$. Growth curves were analyzed in DB interface software and the effect of each compound on growth was evaluated based on the ratio of area under growth curve (compound/control) as "no significant effect (ratio > 0.5)," "inhibition (ratio $\leq 0.5$ )," "static (ratio $=0$, bacterial growth revived after streak on a fresh NBY plate)" and "cidal (ratio $=0$, bacterial growth not revived)” (Wallace et al., 2011).

\section{Germination and Phytotoxicity Assessment of Selected Compounds}

The effect of selected compounds on seed germination and phytotoxicity was evaluated on both tomato and Arabidopsis. Arabidopsis seeds (cv. Columbia) were surface-sterilized by washing with $70 \%$ ethanol-0.05\% Triton for $25 \mathrm{~min}$, followed by $100 \%$ ethanol for $10 \mathrm{~min}$. Molten $1 \%$ water agar was amended with each selected compound at a ratio of 1:100 ( $1 \mu \mathrm{l}$ of $2 \mu \mathrm{mol}$ compound:100 $\mu \mathrm{l}$ water agar) and added to wells of a 96-well plate. Arabidopsis seeds were suspended in sterilized water and $5 \mu \mathrm{l}$ (approximately 10 seeds) was pipetted into each well in a 96-well plate. The germination rate of seed in each well was recorded 5 days later. Similarly, tomato seeds (cv. Tiny Tim) were treated with hot water to eliminate internal and external bacterial phytopathogens (Miller and Ivey, 2005). Five seeds were tested in each well of a 48 well-plate containing $200 \mu \mathrm{M}$ small molecule amended $500 \mu \mathrm{l}$ of $1 \%$ agar. The seed germination rate in each well was recorded 5 days later.

To determine whether a selected compound was phytotoxic, $1 \mu \mathrm{l}$ of $2 \mu \mathrm{mol}$ compound diluted in $100 \mu \mathrm{l}$ water was applied to 10-days-old tomato seedlings in 96-well library tubes and 10-days-old Arabidopsis seedlings in 96-well plates. Death or abnormal growth of seedlings was assessed daily for 5 days. Controls of DMSO (1\%), thymol (1.2\%), and 2, 4-D (2\%) were included in both seed and seedling tests.

\section{Effect of Compounds on Cmm Infection of Tomato Seedlings}

A bioluminescent Cmm strain, BL-Cmm17, was used to monitor the effect of selected small molecules on Cmm infection of tomato seedlings in vivo (Xu et al., 2010). Briefly, tomato seeds (cv. $\mathrm{OH} 9242$ ) were infested by soaking in BL-Cmm17 suspension $\left(10^{8} \mathrm{CFU} / \mathrm{ml}\right)$ in a $100-\mathrm{ml}$ sterile beaker. The beaker was placed in a Nucerite Desiccator (Nalge Sybron Corporation, Rochester, NY, USA), and a vacuum was applied for 5 min using an Air Cadet pump (Barnant, Barrington, IL, USA) with a maximum of $18 \mathrm{lb} / \mathrm{in}^{2}$ pressure. Seeds treated similarly with sterilized water were used as controls. After inoculation, seeds were air-dried and one seed was placed in a $1.2 \mathrm{ml}$ library tube containing $400 \mu \mathrm{l}$ of $1 \%$ water agar; tubes were placed in wells of a 96-well plate. The selected compound ( $1 \mu \mathrm{l}$ of $2 \mu \mathrm{mol}$ in $50 \mu \mathrm{l}$ water) was applied to each seed and the plate was incubated at $25^{\circ} \mathrm{C}$ under $8 \mathrm{~h} / 16 \mathrm{~h}$ light/dark conditions. There were three replicate seeds/plate per treatment. Bioluminescence images were taken using an in vivo imaging system (IVIS Model 100; PerkinElmer, Waltham, MA, USA) 3 and 8 days later. Eight-days-old seedlings were ground in potassium phosphate buffer and extracts were serially diluted and plated on NBY to assess the presence of Cmm.

\section{Cytotoxicity of the Most Potent Compounds}

Caco-2 cells (human colonic carcinoma) were obtained from the American Type Culture Collection, Rockville, $\mathrm{MD}$, and maintained in growth medium [minimal essential medium (MEM) supplemented with $20 \%$ fetal bovine serum (FBS), 1\% non-essential amino acid (NEAA, Invitrogen Life 
Technologies, Grand Island, NY, USA) and with $1 \mathrm{mM}$ sodium pyruvate] at $37^{\circ} \mathrm{C}$ in a humidified, $5 \% \mathrm{CO}_{2}$ incubator. Lactate dehydrogenase (LDH) Cytotoxicity assay was performed following the manufacturer's instructions (LDH Cytotoxicity Assay Kit, Pierce TM, Thermo Scientific, Rockford, IL, USA). Briefly, $\sim 1.4 \times 10^{5}$ cells were grown in a 96-well tissue culture plate with $150 \mu \mathrm{l}$ of growth medium and incubated for $24 \mathrm{~h}$ at $37^{\circ} \mathrm{C}$ in a humidified, $5 \% \mathrm{CO}_{2}$ incubator until a monolayer was completely formed. After three washes with medium without supplements, $1 \mu \mathrm{l}$ of $2 \mu \mathrm{mol}$ compound was added to $100 \mu \mathrm{l}$ of media in each well and incubated for $4 \mathrm{~h}$ at $37^{\circ} \mathrm{C}$ in a humidified, $5 \% \mathrm{CO}_{2}$ incubator. Fifty microlitre of cell supernatant were collected and LDH was measured using the controls indicated by the kit. Blank controls were used by adding $1 \mu \mathrm{l}$ of DMSO and values subtracted from the readings.

\section{Potential for Cmm Acquisition of Resistance to Selected Inhibitory Compounds}

Single step and sequential passage resistance assays were performed as described previously with few modifications (Ling et al., 2015). Eleven of the 12 top hit compounds were tested in this experiment and one could not be resynthesized. The MIC for these 11 compounds was determined using concentrations from 100 to $2.5 \mu \mathrm{M}$. The MBCs for each of these compounds were determined as described previously (Ling et al., 2015). These data were then used for determination of the lethal and sub-lethal doses for resistance studies.

\section{Evaluation of Resistance to Compounds Using Sequential Passage at Sub-lethal Doses}

Clavibacter michiganensis subsp. michiganensis cultures grown in NBY broth medium at $28^{\circ} \mathrm{C}$ for $24 \mathrm{~h}$ were suspended in fresh NBY broth and normalized to an $\mathrm{OD}_{600}$ of $0.01\left(5 \times 10^{6}\right.$ $\mathrm{CFU} / \mathrm{ml}$ ). One-hundred microliters fresh culture was transferred to duplicate wells of a 96-well microtiter plate each containing $0.75 \times$ MIC of a test compound (concentration allowing $>50 \%$ growth inhibition). Cmm cultured in $20 \mu \mathrm{g} / \mathrm{ml}$ chloramphenicol, $50 \mu \mathrm{g} / \mathrm{ml} \mathrm{kanamycin}$, or $2 \%$ DMSO, or non-amended NBY broth were used as controls. The bacteria were incubated at $28^{\circ} \mathrm{C}$, $150 \mathrm{rpm}$, for $24 \mathrm{~h}$ in the dark. Following incubation, plates were centrifuged at $2,100 \times g$ for $5 \mathrm{~min}$ at room temperature. The supernatant was discarded, bacteria were resuspended in $100 \mu \mathrm{l}$ fresh NBY and transferred into a new 96-well plate containing $0.75 \times$ MIC of the same small molecule. This procedure was repeated 14 times. Following 15 passages, bacterial suspensions were assessed for resistance to the test compound by assessing $\mathrm{MIC}$ and $\mathrm{MBC}$ as noted above.

\section{Evaluation of Resistance to Compounds Using a Single Step at a Lethal Dose}

$\mathrm{Cmm}$ grown in NBY medium at $28^{\circ} \mathrm{C}$ for $48 \mathrm{~h}$ was centrifuged at $4,700 \times g$ for $15 \mathrm{~min}$ at room temperature. Supernatant was discarded and bacteria were resuspended in sterile water to a concentration of $\left.2 \times 10^{10} \mathrm{CFU} / \mathrm{ml}\right)$. Compounds $(2 \times \mathrm{MIC})$ were mixed with $1 \mu \mathrm{l}$ of molten NBY agar medium and transferred to duplicate wells of a 24-well culture plate. Agar in the plate was allowed to solidify in the dark. Fifty microlitre of Cmm culture $\left(1 \times 10^{9} \mathrm{CFU}\right)$ was added to test wells, dried in the dark at room temperature, and incubated at $28^{\circ} \mathrm{C}$ for 5 days in the dark. Bacteria spread on NBY agar with $50 \mu \mathrm{g} / \mathrm{ml}$ kanamycin or NBY agar itself was used as positive and negative controls, respectively. After 5 days of incubation, any colonies that developed were assessed for resistance to the test compounds by determining $\mathrm{MIC}$ and the MBC as noted above.

\section{Data Analysis}

To facilitate data analysis, nominal scales on growth inhibition in the secondary screen were transformed to ordinal scores. The compound effect on Cmm growth was scored as "cidal" = 4, "static" = 3, "inhibition" = 2 and "no effect" $=1$, and the effect on plant beneficial bacteria and human gut bacteria growth was scored as "cidal" $=1$, "static" $=2$, "inhibition" $=3$ and "no effect" $=4$. The compound effect on seed germination of tomato and Arabidopsis was scored as "germination rate $(\mathrm{GR})=100 \% "=4$, " $100 \%>\mathrm{GR} \geq 80 \% "=3$, " $80 \%>\mathrm{GR} \geq 50 \% "=2$, "GR $<50 \% "=1$. The total score of each compound was added up from the specificity, sensitivity and phytotoxicity tests carried in the secondary screen. The cytotoxicity of the most potent compounds was analyzed by one-way analysis of variance with mean separation by a least significant difference test at $5 \%$ level of significance in Minitab 16 statistical analysis software.

\section{RESULTS}

\section{Primary Screen Identified 468 Compounds Inhibitory to $\mathbf{C m m}$}

A total of 4,182 small molecules were tested in the primary screen against $\mathrm{Cmm}$ growth in 96-well plates. As all small molecules were dissolved in DMSO, it was important to confirm whether $\mathrm{Cmm}$ growth was affected by DMSO. The supplement of $1 \mu \mathrm{l}$ DMSO in $100 \mu \mathrm{l}$ culture did not significantly affect $\mathrm{Cmm}$ growth in vitro (see Supplementary Figure S1). The initial screen was an evaluation of growth by measuring the end-point $\mathrm{OD}_{595}$ value and the average of the statistical parameter $Z$ '-factor was 0.82 (see Supplementary Figure S2). Z'-factor described the signal window and variation within the positive and negative controls and a $Z^{\prime}$ value higher than 0.5 was considered a robust HTP assay (Zhang et al., 1999). Compounds exhibiting high inhibition of growth ( $>99 \%$ inhibition) were considered candidates for future evaluations. With this criterion, 468 hits were identified in the primary screen (Figure 1). Among these candidates, 350 exhibited a "static" effect, for which Cmm was revived after streaking onto a new NBY plate; and 118 were "cidal" to Cmm growth, in that $\mathrm{Cmm}$ was not revived after streaking.

\section{Compound Prioritization for Further Evaluations}

The purpose of this analysis was to identify compounds that were active against the pathogen and may possess novel mechanisms of action that convey selectivity for a specific pathogen. To 


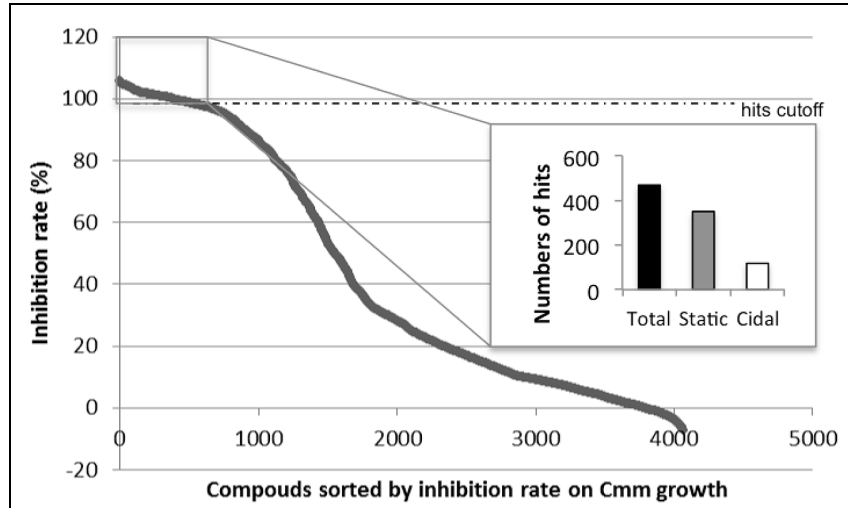

FIGURE 1 | Initial screen of 4,182 compounds against Clavibacter michiganensis subsp. michiganensis strain $\mathbf{C 2 9 0}$ growth. The 468 small molecules with inhibition rate over $99 \%$ were separated based on the effect on $\mathrm{Cmm}$ (350 statics and 118 cidals) and selected as candidates for further analysis.

study the active agents in greater detail, 77 compounds were selected for additional screening. We attempted to ensure that these compounds had acceptable physicochemical properties for further development as potential therapeutic agents by prioritizing those based on: (i) their adherence to Lipinski's rule of 5 (a measure of the drug-likeness of chemical compounds; Lipinski et al., 1997), (ii) meeting the criteria of the golden triangle analysis, and (iii) absence of obvious reactive functional groups. Additional selection criteria include the ability to rapidly functionalize the molecule through synthetic methods and the novelty of the structure. Based on these criteria, the unique compounds with bactericidal activity have been the primary focus of this effort. For this reason, several of these compounds were included with the compounds selected for additional screening.

\section{Sensitivity and Specificity of Selected Compounds}

In the secondary screen, compounds were evaluated by kinetic measurement of $\mathrm{Cmm}$ growth over $24 \mathrm{~h}$ instead of end-point measurement used in the primary screen (see Supplementary Figure S3). All the 77 selected compounds showed either a cidal or static effect on the five groups of $\mathrm{Cmm}$ strains tested, which confirmed the reproducibility of the results from the primary screen. Forty-eight of the candidates (62\%) were cidal to all $\mathrm{Cmm}$ strains and $33 \%$ were cidal to at least three groups of Cmm strains (Figure 2).

While testing the compounds for MIC against $\mathrm{Cmm}$, we found that cidality was concentration-dependent; half of compounds were not effective at $25 \mu \mathrm{M}$; at $12.5 \mu \mathrm{M}$ four candidates remained cidal (Figure 3A). To assess the specificity of the compounds, they were screened at $200 \mu \mathrm{M}$ concentration against Pseudomonas fluorescens and Lysobacter enzymogenes (plant commensal bacteria), and Bifidobacterium animalis, E. coli, and Lactobacillus rhamnosus (human gut commensal bacteria). Most compounds did not significantly affect the growth of plant and

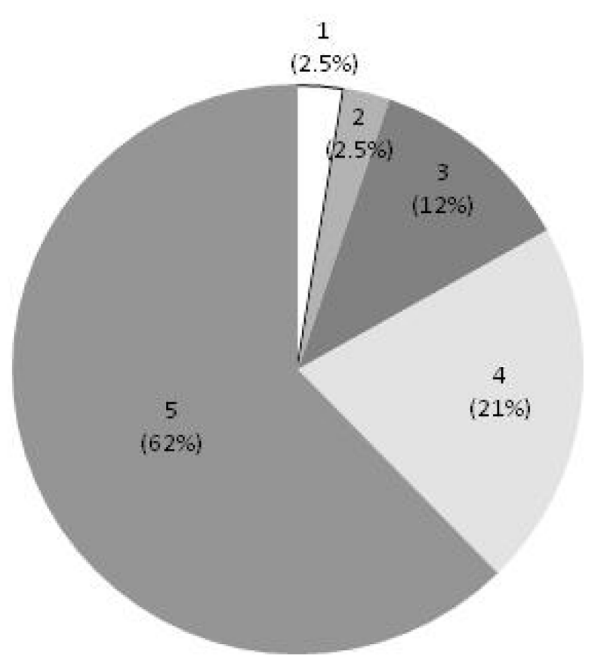

FIGURE 2 | Effect of selected compounds on multiple C. michiganensis subsp. michiganensis $(\mathbf{C m m})$ strains. Score $5=$ cidal to five groups of $\mathrm{Cmm}$ strains, $4=$ cidal to four groups of $\mathrm{Cmm}$ strains, 3 = cidal to three groups of $\mathrm{Cmm}$ strains, $2=$ cidal to two groups of $\mathrm{Cmm}$ strains, $1=$ cidal to 1 group of $\mathrm{Cmm}$ strains.

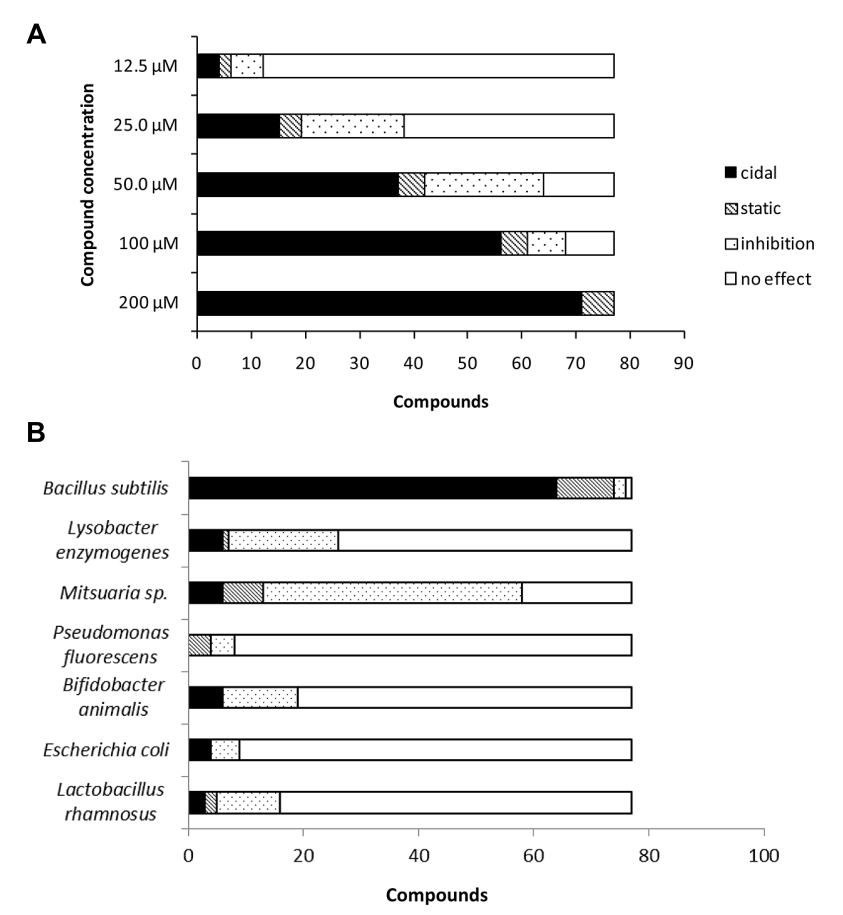

FIGURE 3 | (A) Effect of serially diluted compounds on C. michiganensis subsp. michiganensis growth. (B) Effect of selected compounds on growth of plant beneficial bacteria and human gut bacteria.

human beneficial bacteria (Figure 3B). In contrast, the growth of the plant rhizospheric bacterium $B$. subtilis was completely inhibited by most compounds and the growth of Mitsuaria sp. was affected by more than half of the candidates. 
TABLE 2 | Effect of selected compounds on Arabidopsis and tomato seed germination.

\begin{tabular}{lccc}
\hline Germination rate (\%) & Score & \multicolumn{2}{c}{ Number of compounds } \\
\cline { 3 - 4 } & & Arabidopsis & Tomato \\
\hline 100 & 4 & 24 & 71 \\
$80 \leq \mathrm{GR}<100$ & 3 & 17 & 1 \\
$50 \leq \mathrm{GR}<80$ & 2 & 15 & 2 \\
$<50$ & 1 & 21 & 3 \\
\hline
\end{tabular}

\section{Phytotoxicity of the Selected Compounds}

Some compounds reduced the germination of Arabidopsis seeds. All non-treated Arabidopsis seeds germinated, whereas the rate of germination for seeds treated with DMSO alone was $85 \%$. Forty-one of 77 (53\%) compounds had no or little effect on Arabidopsis germination ( $\geq 80 \%), 15$ candidates moderately reduced germination (50-100\%), and 21 candidates reduced germination rates to less than 50\% (Table 2).

The majority of hit compounds (93\%) did not affect tomato seed germination compared to untreated and DMSO controls. The germination rate of tomato control seeds, both non-treated and DMSO treated was $100 \%$. Only six compounds reduced germination less than $80 \%$. Compounds applied to seedlings did not cause deformation or death in either Arabidopsis or tomato. Together the data on both Arabidopsis and tomato seeds suggest that the majority of the compounds are specific to bacteria at the doses tested.

\section{Efficacy of Selected Compounds in Controlling $\mathrm{Cmm}$ on Tomato Seed}

$\mathrm{Cmm} \mathrm{BL-Cmm17} \mathrm{is} \mathrm{a} \mathrm{virulent} \mathrm{bioluminescent} \mathrm{strain} \mathrm{carrying}$ luxCDABE and is a useful reporter because the strength of luminescent signals is positively correlated with the number of live cells (Xu et al., 2010). Bioluminescent imaging of inoculated tomato seedlings showed that the non-treated, infected tomato seedlings exhibited high luminescent signals compared to Cmminoculated seedlings treated with most compounds. Seedlings treated with nine of 77 compounds exhibited high luminescent signals, indicating that these compounds did not inhibit $\mathrm{Cmm}$ infection (Figure 4). However, half of the compounds reduced the tomato $\mathrm{Cmm}$ burden by over $0.5 \log \mathrm{CFU} ; 10$ compounds reduced $\mathrm{Cmm}$ populations by $1 \mathrm{log}$ or greater (Figure 5).

The minimum and maximum sum scores for specificity, sensitivity and phytotoxicity in the secondary screen were 14 and 57, whereas the actual score ranged from 25 to 53 . A scatter plot of the compound scores versus effect on Cmm seedling infection allowed us to categorize these compounds into four groups (Figure 5). The most potent compounds were identified by considering both the effect on reduction of $\mathrm{Cmm}$ infection in seedlings and high score in the secondary screens. Thus, compounds 1 to 12 from Groups A, B, and $\mathrm{C}$ were considered to have a strong potential for bactericide development. The chemical structures of the 12 compounds falls into five distinct classes: piperidines, benzimidazole, phenols, phenoxy isopropanolamines, and pyrrolidones (Figure 6).

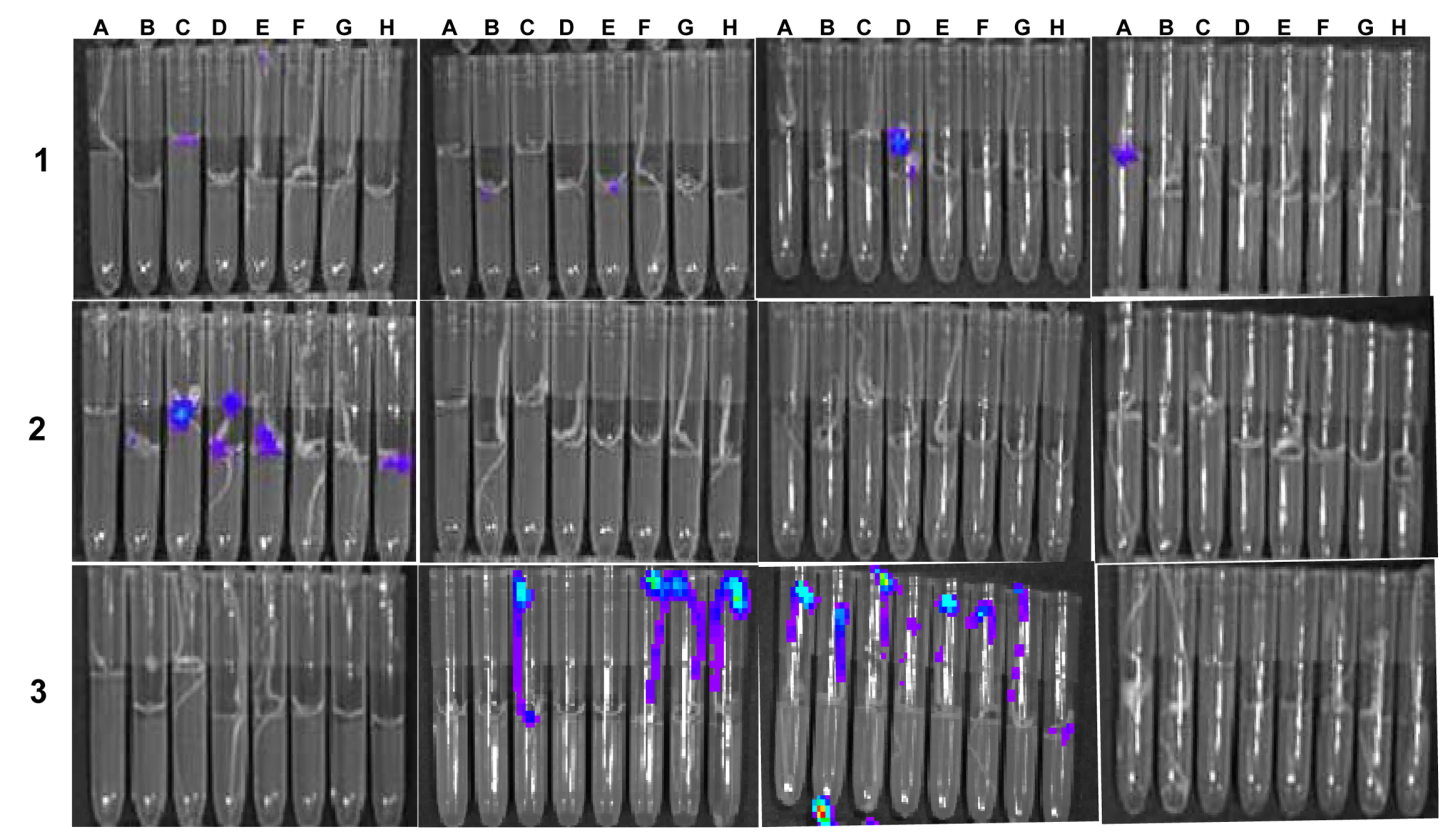

FIGURE 4 | Bioluminescence imaging of tomato seed infested with C. michiganensis subsp. michiganensis (Cmm) BL-Cmm17 and treated with selected small molecules in 96-well library tubes. Image was taken of 8-days-old seedlings with an in vivo imaging system. Tubes in rows 1 , 2 , and 3 contained Cmm-infested seeds treated with small molecules; seeds in row 3, column 2 ( $F, G, H)$ were Cmm-infested and treated with DMSO; seeds in row 3 , column 3 (A through $\mathrm{H}$ ) were $\mathrm{Cmm}$-infested and not treated with small molecules; and seeds in row 3, column 4 (A through $\mathrm{H}$ ) were not non-inoculated with $\mathrm{Cmm}$. 


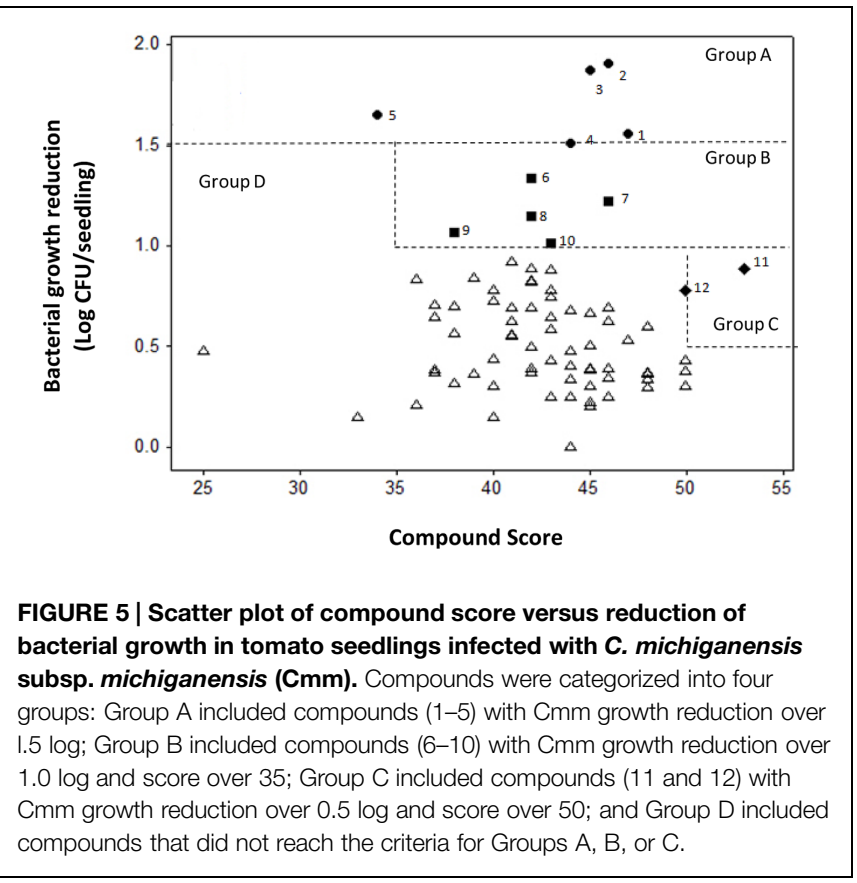

\section{Cytotoxicity of Selected Compounds}

Cytotoxicity was evaluated using cultured mammalian cells to explore the potential future application of these selected compounds on tomato for consumption. The 12 compounds tested showed a range of cytotoxicity of $8.4-46.6 \%$ in the cytotoxicity assay (Figure 7), compared to the lysis buffer control. These results suggested that the most potent compounds show varying degrees of specificity to bacteria with minor degrees of general toxicity.

\section{Potential for $\mathrm{Cmm}$ Acquisition of Resistance to Selected Inhibitory Compounds}

Lethal and sub-lethal doses of eleven candidate compounds were determined (Table 3). Cmm was killed or inhibited at concentrations ranging from 5 to $100 \mu \mathrm{M}$ depending on the small molecule; the MIC and MBC were the same for seven molecules; for three compounds the MBC was onefold higher than the MIC; and for only one compound the MBC was twofold higher than the MIC. After incubation on solid media amended with a lethal dose of the target compound for 5 days, no resistant $\mathrm{Cmm}$ colonies were observed for any of the 11 compounds tested (Table 3). Following $\mathrm{Cmm}$ incubation at sub-lethal doses in liquid media during 15 passages, identical MICs and MBCs were observed for bacteria that grew at the sub-lethal concentration of small molecules (Table 3). This suggests that the 11 novel compounds were unlikely to induce resistance in $\mathrm{Cmm}$ under the tested conditions; however, for commercial approval of these antimicrobials, more in-depth characterization of potential resistance is warranted.

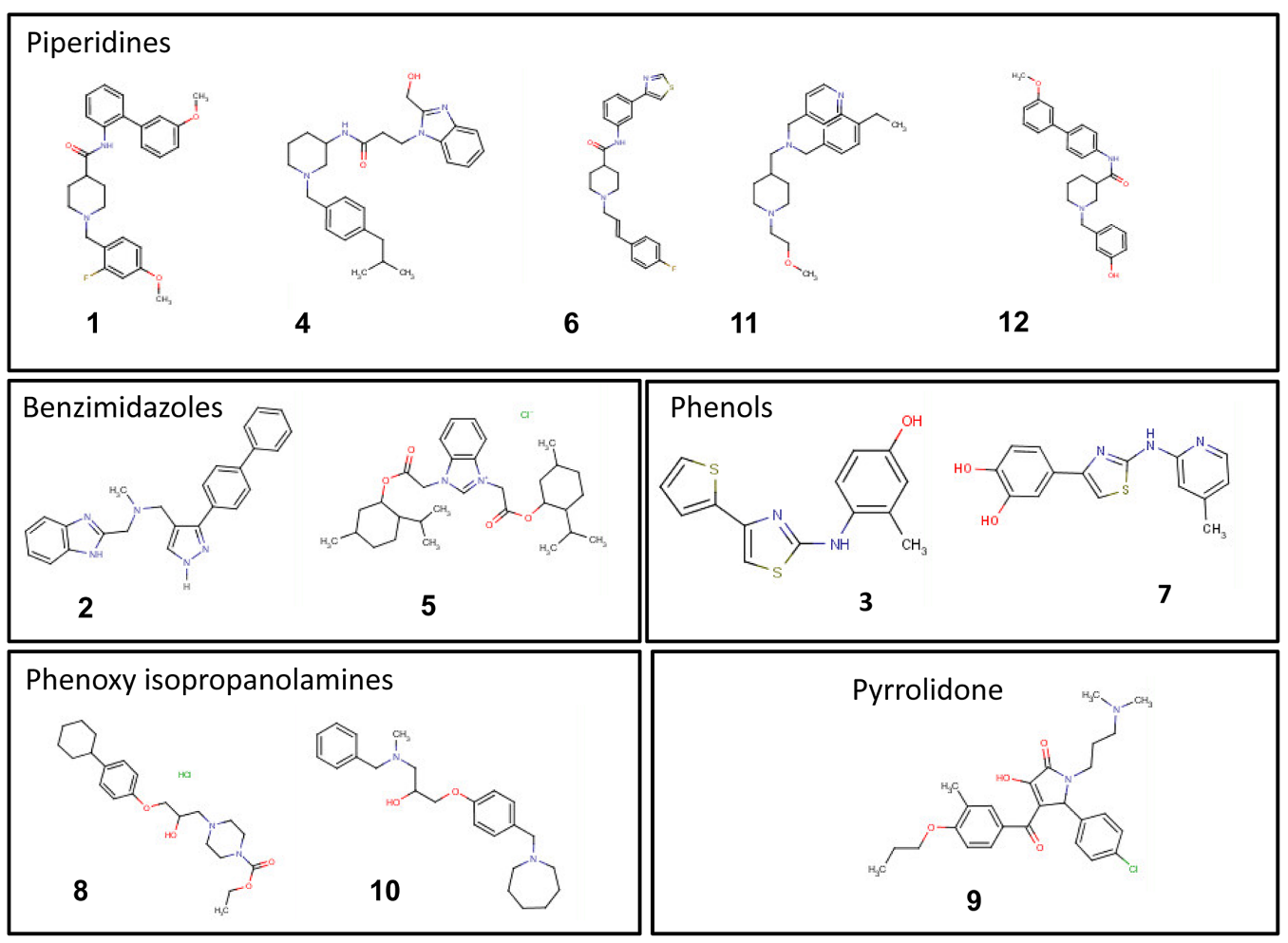

FIGURE 6 | Chemical structures of the top 12 potent small molecules inhibitory to $C$. michiganensis subsp. michiganensis identified in this study. 


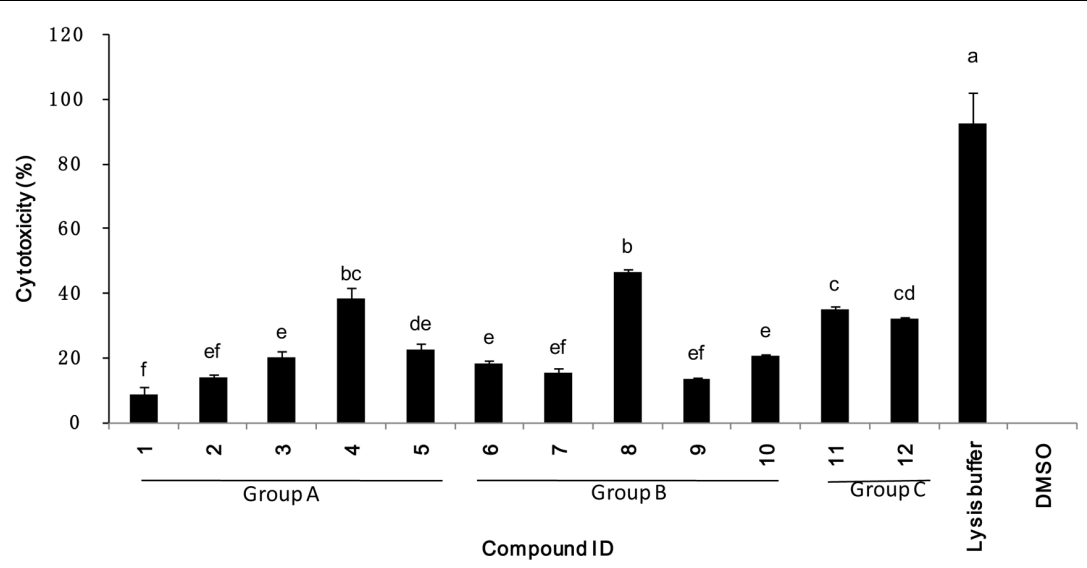

FIGURE 7 | Percentage mammalian cytotoxicity of the $\mathbf{1 2}$ top potent compounds. Cytotoxicity was assessed using Caco- 2 cells exposed to $200 \mu \mathrm{M}$ of compound for 4 h. Groups A, B, and C refers to compounds classification described in Figure $\mathbf{5}$.

TABLE 3 | Minimum inhibitory concentration (MIC), MBC, and potential induction of resistance in $\mathrm{Cmm}$ to the 11 selected small molecules.

\begin{tabular}{lcccl}
\hline $\boldsymbol{N}^{\circ}$ & $\begin{array}{c}\text { MICs } \\
(\boldsymbol{\mu} \mathbf{M})\end{array}$ & $\begin{array}{c}\text { MBCs } \\
(\boldsymbol{\mu} \mathbf{M})\end{array}$ & $\begin{array}{c}\text { Resistant colonies } \\
\text { after growth at } \\
\text { sub-lethal (0.75X MIC) } \\
\text { concentration }\end{array}$ & $\begin{array}{c}\text { Resistant colonies } \\
\text { after incubation at } \\
\text { lethal (2X MIC) } \\
\text { concentration }\end{array}$ \\
\hline 1 & 25 & 25 & None & None \\
2 & 25 & 50 & None & None \\
3 & 50 & 50 & None & None \\
4 & 100 & 100 & None & None \\
5 & 5 & 5 & None & None \\
6 & 50 & 50 & None & None \\
7 & 50 & 50 & None & None \\
8 & 50 & 50 & None & None \\
9 & 50 & 100 & None & None \\
11 & 25 & 100 & None & None \\
12 & 12.5 & 25 & &
\end{tabular}

aResistance to compounds was determined after 15 passages in liquid media; ${ }^{\mathrm{b}}$ Resistance to compounds was determined after 5 days growth on solid media.

\section{DISCUSSION}

Here, we report on the results of an HTP-growth screen to identify novel anti-Cmm compounds. We identified 12 such drug-like small molecule compounds that satisfied our predefined criteria. The initial goal of the project was to: (i) exploit the pre-selected library to identify hits that completely inhibit the growth of $\mathrm{Cmm}$; (ii) further discover such small molecules that vary in growth inhibition of $\mathrm{Cmm}$ and other bacteria using a kinetic study as previously described (Wallace et al., 2011); and (iii) test these small molecules on pathogen infection in the host. By using a library of prescreened, bioactive compounds, we and others have found that the hit rate in such screens against untested organisms is increased between 4- and 12-fold (Lieberman and Higgins, 2009; Wallace et al., 2011). Specifically we chose the yeast active "yactive" library, and screened approximately 4,200 of the 7,500 compounds (selected from a total of 81,000 compounds) that we have previously shown inhibitory to Saccharomyces cerevisiae growth by at least $30 \%$. Consistent with the reported increase in hit-rate with this library, the hit rate in this study was high $(11.1 \%)$, despite the strict threshold criteria we used to select candidates based on $\mathrm{Cmm}$ growth inhibition.

Depending on the screening purpose, different cellular and molecular high throughput screening (HTS) approaches have been developed, and each has different criteria for hit selection. For example, according to a study performed at $12.5 \mu \mathrm{M}$, hit rates of $0.024 \%$ for $E$. coli and $0.005 \%$ for $P$. aeruginosa were observed (De La Fuente et al., 2006). Our study for complete $\mathrm{Cmm}$ inhibition by 77 selected compounds (also performed at $12.5 \mathrm{uM}$ ), in contrast, showed numbers comparable to classical antibiotics and were 46-fold higher than those reported for E. coli.

Compared to the end-point value used in the primary screen, the area under the growth curve calculated by kinetic measurement of growth provides more quantitative data to evaluate compound effect on growth inhibition (Wallace et al., 2011). Therefore, in our secondary screen, we tested the selected 77 compounds on additional $\mathrm{Cmm}$ strains as well as other bacteria using a kinetic OD reader. As expected, the majority of compounds showed cidal effect on growth of multiple $\mathrm{Cmm}$ strains, but some compounds were static rather than cidal to diverse strains. Since the $\mathrm{Cmm}$ strains were collected from different geographic locations and also presented different DNA fingerprint profiles, their compound sensitivity is likely due to their genetic diversity. Interestingly, testing the compounds on other plant beneficial bacteria and human gut bacteria showed that most compounds were cidal against the Gram-positive bacterium B. subtilis, but had little or no effect on the Gramnegative bacteria tested. Based on this observation, we suggest that the compounds tested in the secondary screen may disrupt the cell membrane structure, cell wall synthesis or metabolic activity specific to Gram-positive bacteria.

The cell-based HTP screens rely on bacterial growth inhibition, hence they will miss virulence genes that when 
inhibited do not show a growth defect. However, our rapid, highthroughput, in vivo imaging assessment of $\mathrm{Cmm}$ infection in tomato may provide a complementary way to identifying small molecules that influence virulence genes or induce plant defenses.

The top 12 drug-like compounds populate five distinct classes (Figure 6). The benzimidazole-containing compound carbendazim is a well-known fungicide widely used in agricultural production (Zikos et al., 2015). In addition, recently the benzimidazole class of compounds have been shown to inhibit a G+ bacterium, Staphylococcus aureus by targeting DNA gyraseB enzyme (Janupally et al., 2014). We have found two benzimidazole compounds (2 and 5) with specific anti-Cmm activity. In particular, compound \#5 with a lower score in the secondary screen exhibited a broader antibacterial spectrum compared with other 11 compounds in this study (data not shown). A few phenolic compounds have been studied for their antimicrobial activity and two natural phenols were less effective against Gram-negative bacteria than Gram-positive bacteria (King et al., 1972). In addition, a phenol drug was found to inhibit B. subtilis growth by interfering with cell wall synthesis (Shimi et al., 1976). Consistent with this, we identified two phenol compounds, \#3 and \#7, which were cidal to both $\mathrm{Cmm}$ and B. subtilis, but not to the Gram-negative bacteria tested. Hence, we suspect that these phenols have a similar mode of action. Almost half of the 12 top potent compounds belong to piperidines, however, there are very few reports on this class of compounds. A recent study claimed piperidines to

\section{REFERENCES}

Aiello, D., Williams, J. D., Majgier-Baranowska, H., Patel, I., Peet, N. P., Huang, J., et al. (2010). Discovery and characterization of inhibitors of Pseudomonas aeruginosa type III secretion. Antimicrob. Agents Chemother. 54, 1988-1999. doi: 10.1128/AAC.01598-09

Arnoldo, A., Curak, J., Kittanakom, S., Chevelev, I., Lee, V. T., Sahebol-Amri, M., et al. (2008). Identification of small molecule inhibitors of Pseudomonas aeruginosa exoenzyme S using a yeast phenotypic screen. PLoS Genet. 4:e1000005. doi: 10.1371/journal.pgen.1000005

Carlton, W. M., Braun, E. J., and Gleason, M. L. (1998). Ingress of Clavibacter michiganensis subsp. michiganensis into tomato leaves through hydathodes. Phytopathology 88, 525-529. doi: 10.1094/PHYTO.1998.88.6.525

Chang, R. J., Ries, S. M., and Pataky, J. K. (1991). Dissemination of Clavibacter michiganensis subsp. michiganensis by practices used to produce tomato transplants. Phytopathology 81, 1276-1281. doi: 10.1094/Phyto-81-1276

Cooskey, D. A. (1990). Genetic of bactericide resistance in plant pathogenic bacteria. Annu. Rev. Phytopathol. 28, 201-219. doi: 10.1146/annurev.py.28.090190.001221

De La Fuente, R., Sonawane, N. D., Arumainayagam, D., and Verkman, A. S. (2006). Small molecules with antimicrobial activity against E. coli and P. aeruginosa identified by high-throughput screening. Br. J. Pharmacol. 149, 551-559. doi: 10.1038/sj.bjp.0706873

Gartemann, K. H., Kirchner, O., Engemann, J., Gräfen, I., Eichenlaub, R., and Burger, A. (2003). Clavibacter michiganensis subsp. michiganensis: first steps in the understanding of virulence of a Gram-positive phytopathogenic bacterium. J. Biotechnol. 106, 179-191. doi: 10.1016/j.jbiotec.2003.07.011

Gleason, M. L., Gitaitis, R. D., and Ricker, M. D. (1993). Recent progress in understanding and controlling bacterial canker of tomato in Eastern North America. Plant Dis. 77, 1069-1076. doi: 10.1094/PD-77-1069

Hausbeck, M. J., Bell, J., Medina-Mora, C., Podolsky, R., and Fulbright, D. W. (2000). Effect of bactericides on population sizes and spread of Clavibacter possess antimicrobial effects (Patel et al., 2012). Only one of the top compounds, \#9, fell into pyrrolidone class, but several previous studies have described pyrrolidone derivatives against human bacterial pathogens (Phaechamud et al., 2012; Sathiyanarayanan et al., 2014). Compounds \#8 and \#10 were the first phenoxy isopropanolamines reported to have antibacterial activity.

In summary, we have identified 12 anti-Cmm drug-like compounds and future work on increasing the efficacy of the compounds by downstream modification, target identification and biologically active functional groups must be explored.

\section{ACKNOWLEDGMENTS}

This work was supported by USDA NIFA Specialty Crop Research Initiative project number 2010-51181-21415, OSUOARDC SEEDS grants, and a grant from the CIHR to CN. We thank Dr. Brian McSpadden Gardener at The Ohio State University for providing the plant beneficial bacteria strains for this study.

\section{SUPPLEMENTARY MATERIAL}

The Supplementary Material for this article can be found online at: http://journal.frontiersin.org/article/10.3389/fmicb. 2015.01127

michiganensis subsp. michiganensis on tomatoes in the greenhouse and on disease development and crop yield in the field. Phytopathology 90, 39-44. doi: 10.1094/PHYTO.2000.90.1.38

Hong-Geller, E., and Micheva-Viteva, S. (2013). "Small molecule to identify inhibitors of infectious disease," in Drug Discovery, ed. H. A. El-Shemy (Rijeka: InTech Press), 157-175.

Janupally, R., Jeankumar, V. U., Bobesh, K. A., Soni, V., Devi, P. B., Pulla, V. K., et al. (2014). Structure-guided design and development of novel benzimidazole class of compounds targeting DNA gyraseB enzyme of Staphylococcus aureus. Bioorg. Med. Chem. 22, 5970-5987. doi: 10.1016/j.bmc.2014.09.008

Junker, L. M., and Clardy, J. (2007). High-throughput screens for small-molecule inhibitors of Pseudomonas aeruginosa biofilm development. Antimicrob. Agents Chemother. 51, 3582-3590. doi: 10.1128/AAC.00506-07

Kamau, E. T., Srinivasan, A. R., Brown, M. J., Fair, M. G., Caraher, E. J., and Boyle, J. P. (2012). A focused small-molecule screen identifies 14 compounds with distinct effects on Toxoplasma gondii. Antimicrob. Agents Chemother. 56, 5581-5590. doi: 10.1128/AAC.00868-12

Kawaguchi, A., Tanina, K., and Inoue, K. (2010). Molecular typing and spread of Clavibacter michiganensis subsp. michiganensis in greenhouses in Japan. Plant Pathol. 59, 76-83. doi: 10.1111/j.1365-3059.2009.02207.x

King, A. D., Bayne, H. G., Jurd, L., and Case, C. (1972). Antimicrobial properties of natural phenols and related compounds: obtusastyrene and dihydro-obtusastyrene. Antimicrob. Agents Chemother. 1, 263-266. doi: 10.1128/AAC.1.3.263

Lieberman, L. A., and Higgins, D. E. (2009). A small-molecule screen identifies the antipsychotic drug pimozide as an inhibitor of Listeria monocytogenes infection. Antimicrob. Agents Chemother. 53, 756-764. doi: 10.1128/AAC.00607-08

Ling, L. L., Schneider, T., Peoples, A. J., Spoering, A. L., Engels, I., Conlon, B. P., et al. (2015). A new antibiotic kills pathogens without detectable resistance. Nature 22, 455-459. doi: 10.1038/nature14098

Lipinski, C. A., Lombardo, F., Dominy, B. W., and Feeney, P. J. (1997). Experimental and compu-tational approaches to estimate solubility and 
permeability in drug discoveryand development settings. Adv. Drug Deliv. 23, 3-25. doi: 10.1016/S0169-409X(96)00423-1

Louws, F., Bell, J., Medina-Mora, C., Smart, C. D., Opgenorth, D., Ishimaru, C., et al. (1998). Rep-PCR-mediated genomic finger-printing: a rapid and effective method to identify Clavibacter michiganensis subsp. michiganensis. Phytopathology 88, 862-868. doi: 10.1094/PHYTO.1998.88.8.862

Miller, S. A., and Ivey, M. L. (2005). Hot Water and Chlorine Treatment of Vegetable Seeds to Eradicate Bacterial Plant Pathogens. The Ohio State University Extension. HYG-3085-05. Available at: http://ohioline.osu.edu/hyg-fact/3000/ 3085.html

Patel, D., Patel, R., Kumari, P., and Patel, N. (2012). Microwave-assisted synthesis of coumarin based 1,3,5-triazinyl piperazines and piperidines and their antimicrobial activities. Acta Pol. Pharm. 69, 879-891.

Pereira, M. P., Blanchard, J. E., Murphy, C., Roderick, S. L., and Brown, E. D. (2009). High-throughput screening identifies novel inhibitors of the acetyl transferase activity of Escherichia coli GlmU. Antimicrob. Agents Chemother. 53, 2306-2311. doi: 10.1128/AAC.01572-08

Phaechamud, T., Mahadlek, J., Charoenteeraboon, J., and Choopun, S. (2012). Characterization and antimicrobial activity of $\mathrm{N}$-methyl-2-pyrrolidone-loaded ethylene oxide-propylene oxide block copolymer thermosensitive gel. Indian J. Pharm. Sci. 74, 498-504. doi: 10.4103/0250-474X.110574

Sathiyanarayanan, G., Gandhimathi, R., Sabarathnam, B., Seghal, K. G., and Selvin, J. (2014). Optimization and production of pyrrolidone antimicrobial agent from marine sponge-associated Streptomyces sp. MAPS15. Bioprocess Biosyst. Eng. 37, 561-573. doi: 10.1007/s00449-013-1023-2

Schreiber, K. J., Ckurshumova, W., Peek, J., and Desveaux, D. (2008). A highthroughput chemical screen for resistance to Pseudomonas syringae in Arabidopsis. Plant J. 54, 522-531. doi: 10.1111/j.1365-313X.2008.03425.x

Schreiber, K. J., Nasmith, C. G., Allard, G., Singh, J., Subramaniam, R., and Desveaux, D. (2011). Found in translation: high-throughput chemical screening in Arabidopsis thaliana identifies small molecules that reduce Fusarium head blight disease in wheat. Mol. Plant Microbe Interact. 24, 640-648. doi: 10.1094/MPMI-09-10-0210

Sharabani, G., Manulis-Sasson, S., Borenstein, M., Shulhani, R., Lofthouse, M., Chalupowicz, L., et al. (2013). The significance of guttation in the secondary spread of Clavibacter michiganensis subsp. michiganensis in tomato greenhouses. Plant Pathol. 62, 578-586. doi: 10.1111/j.1365-3059.2012. 02673.x

Shimi, I. R., Shoukry, S., and Zaki, Z. (1976). 4,4'-isopropylidine-bis(2isopropyl)phenol, a new inhibitor for cell wall formation of Bacillus subtilis. Antimicrob. Agents Chemother. 9, 580-584. doi: 10.1128/AAC.9. 4.580

Wallace, I. M., Urbanus, M. L., and Luciani, G. M. (2011). Compound prioritization methods increase rates of chemical probe discovery in model organisms. Chem. Biol. 18, 1273-1283. doi: 10.1016/j.chembiol.2011.07.018

Xu, X., Miller, S. A., Baysal-Gurel, F., Gartemann, K. H., Eichenlaub, R., and Rajashekara, G. (2010). Bioluminescence imaging of Clavibacter michiganensis subsp. michiganensis infection of tomato seeds and plants. Appl. Environ. Microbiol. 76, 3978-3988. doi: 10.1128/AEM.00493-10

Zhang, J. H., Chung, T. D., and Oldenburg, K. R. (1999). A simple statistical parameter for use in evaluation and validation of high throughput screening assays. J. Biomol. Screen. 4, 67-73. doi: 10.1177/1087057199004 00206

Zikos, C., Evangelou, A., Karachaliou, C. E., Gourma, G., Blouchos, P., Moschopoulou, G., et al. (2015). Commercially available chemicals as immunizing haptens for the development of a polyclonal antibody recognizing carbendazim and other benzimidazole-type fungicides. Chemosphere 119(Suppl.), S16-S20. doi: 10.1016/j.chemosphere.2014.03.049

Conflict of Interest Statement: The authors declare that the research was conducted in the absence of any commercial or financial relationships that could be construed as a potential conflict of interest.

Copyright $\odot 2015 \mathrm{Xu}$, Kumar, Deblais, Pina-Mimbela, Nislow, Fuchs, Miller and Rajashekara. This is an open-access article distributed under the terms of the Creative Commons Attribution License (CC BY). The use, distribution or reproduction in other forums is permitted, provided the original author(s) or licensor are credited and that the original publication in this journal is cited, in accordance with accepted academic practice. No use, distribution or reproduction is permitted which does not comply with these terms. 